\title{
Knowledge of substance abuse among students studying in a selected higher secondary school in Biratnagar city
}

\author{
Neela Subba ${ }^{1}$, Dipty Subba ${ }^{2 *}$ and Sushmita Raj Shah ${ }^{3}$ \\ ${ }^{1}$ Nursing Campus, TUIOM, Biratnagar, Nepal \\ ${ }^{2}$ PUCMAS, Gothgaun, Morang, Nepal \\ ${ }^{3}$ BPKIHS, Dharan, Sunsari, Nepal \\ *E-mail: diptysubba@hotmail.com
}

\begin{abstract}
This was a cross sectional study carried out to among 115 students aged between 15-20 years of grade 12. The objective of the study was to assess the knowledge of substance abuse among students studying in selected higher secondary school of birtnagar. Students were selected by purposive sampling technique. A pretested semi structured questionnaire related to demographic and knowledge was administered and data were collected by self-administered method. The data was analyzed and interpreted by using simple descriptive and inferential statistics. Among the respondents $53 \%$ were male and $47 \%$ of them were female with the mean age of 18 years. Although, majority of respondents $(51.3 \%)$ answered correctly regarding the meaning of substance, only $19.1 \%$ knew the actual meaning of substance abuse. Among them, $87.88 \%$ had good knowledge, $11.12 \%$ had average knowledge and only $2.6 \%$ had poor knowledge on over all substance abuse. The main source of information as perceived by students was peer group and media. Many of the students agreed as peer pressure $(53.9 \%)$ one of the main cause for substance abuse. None of the respondents had ever taken any kinds of drugs or any other substances.
\end{abstract}

Key words: Drug, abuse, students

\section{Introduction}

The use of drug including alcohol began as a part of tribal ritual. Today, people use drugs to overcome tension (Tsering et al., 2010), relieve pain (Trumbull Country Report) and to attain of pleasure (Webb et al., 1996). Substance abuse among adolescents and young adults are increasing like an epidemic. Many have experimented various drug. Problem started or began to arise when this experimental use became abuse, effecting individual health, family and society and creating criminal and legal problems, leading to national productivity and economy (Kumar, 2008). Those abusive problems usually begin in adolescence, the time for discovery and challenge and experimentation. Adolescents are poly substance abuser; "gateway" drugs like tobacco, alcohol and marijuana, nicotine leads to "open the gates" to further heavier drug for teens. To the young persons, choice of drug is often related to "drug fashion".

In Nepal is not an indigenous problem. It was brought here by the "Hippies" during the early 1970s. Gradually, the problem began to spread and now is estimated 50,000 people in Nepal are drug addicts and most of them are between 15-30 years of age. In a survey conducted by Narcotic Drug Control Division of the Ministry of Home Affairs, the problem of HIV positive is very common among drug abusers and almost 40 percent abusers are infected. In Nepal, the majority of drug users start 40,000 to 50,000 with Marijuana and Phensidyl from the age of 15 to 16 years. Especially, young Nepalese addicts come from different strata of society. Research findings show they come from upper income group (UNAIDS, 2001). 


\section{Materials and Methods}

This small scale, cross sectional survey was on $12^{\text {th }}$ grade students from selected higher secondary school of Biratnagar. One hundred and fifteen students participated in this survey. Consent was taken from both school authority and the students. A pretested semi structured questionnaire related to demographic and knowledge related to substance abuse was administered and data were collected by self-administered method. The questionnaire was personally administered during scheduled lecture hours and almost all the students participated. Data was analyzed by computer program SPSS. The data was analyzed and interpreted by using simple descriptive and inferential statistics.

\section{Results and Discussion}

The characteristics of the demographic variables as shown in table 1 in terms of their frequency and percentage distribution which showed that students age ranges from 15 to 20 years with the mean age of adolescents is 18 years. 61 (53\%) were male students. Most of them (55.7\%) are permanent residents of Biratnagar. $72.2 \%$ belonged to nuclear family and $56.5 \%$ comes from low class family (income up to Rs 10,000 per month); this finding is similar to earlier report (Rather et al., 2013).

Table 1. Frequency and percentage distribution of respondents demographic variables. $(\mathrm{N}=115)$

\begin{tabular}{ccc}
\hline Variables & Frequency & Percentage \\
\hline Age (in years) & 2 & \\
15 & 16 & 1.7 \\
16 & 41 & 13.9 \\
17 & 43 & 35.7 \\
18 & 9 & 7.6 \\
19 & 4 & 3.5 \\
20 & & \\
Gender & 61 & 53 \\
Male & 54 & 47 \\
Female & & \\
Residence & 64 & 55.7 \\
Permanent & 51 & 44.3 \\
Temporary & & \\
Family type & 83 & 72.2 \\
Nuclear & 28 & 24.3 \\
Joint & 4 & 3.5 \\
Extended & & \\
\hline
\end{tabular}

Among the students of class $12,98 \%$ had knowledge regarding substance abuse where $87.82 \%$ had good knowledge, $11.17 \%$ had average knowledge and only $2.6 \%$ had poor knowledge as shown in Figure 1. This rate varies widely with the other study findings (Arasumani, 2013). When the knowledge compared with gender, it was found to be equal this result is in parallel with the results of some similar studies done in college at Eldoret (Atwoli et al., 2011) at a college in Jordan (Haddad et al., 2010) but different from the results of some other studies done in Bangladeshi students (Masibo et al., 2013) and a study by Sharma (2001) which shows higher knowledge in female than male students. 
Sources of information regarding substance abuse was from media (Tsering et al., 2010), friends, school and internet was $58.4 \%, 67 \%, 44.3 \%$, and $34.8 \%$, respectively.

Although, majority of respondents (51.3\%) answered correctly regarding the meaning of substance, only $19.1 \%$ knew the actual meaning of substance abuse as maladaptive pattern of substance use.

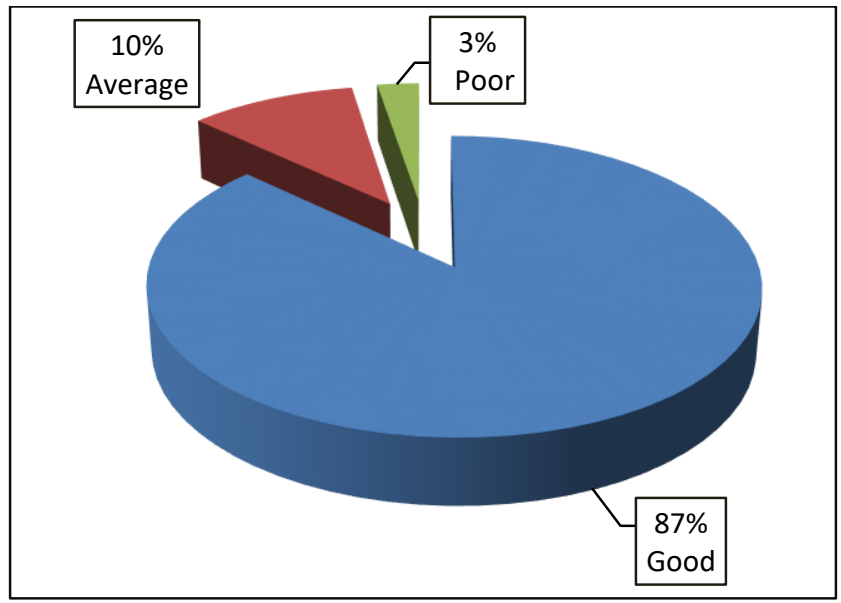

Figure 1. Percentage distribution of knowledge level regarding substance abuse.

The majority of participants have more than one cause of substance abuse and the major cause is peer pressure (53.5\%) which is similar to the study of Zaman et al. (2013) and Gupta et al. (2013).

It may be concluded that the most of the students have good knowledge about the substance abuse. Despite the findings, adolescence is the period of transition, facing challenges and adjustment to different changes, there are chances that they might with one or some other reason can indulge to substance use. As suggested by the respondents in this study, education and awareness (53\%) and support and guidance (37\%) can prove to be panacea.

\section{References}

Arasumani N. 2013. A study on knowledge and attitude among late adolescents towards a alcoholism in selected colleges in Banglore. Journal of Science 3(2): 59-61.

Atwoli, L., Prisca A Mungla, Moses N Ndung'u, Kiende C Kinoti \& Evans M Ogot. 2011. Prevalence of substance use among college students in Eldoret, western Kenya. BMC Psychiatry. 11: 34. doi: 10.1186/1471-244X-11-34. PMCID: PMC3053226

Gupta, S., Sandeep Singh Sarpal, Dinesh Kumar, Tarundeep Kaur \& Sumant Arora. 2013. Prevalence, Pattern and Familial Effects of Substance Use among the Male College Students - A North Indian Study. J. Clin Diagn Res. 7(8): 1632-1636. doi: 10.7860/ JCDR/2013/6441 .3215

Haddad. L., Shotar. A, Umalauf. M, \& S. Al-Zyard. 2010. Knowledge of substance abuse among high school students in Jordan. J Transcult Nurs 21(2): 143-150. doi: 10.1177/104365960 9357632 ten.sagepub.com/content/21/2/143. 
Masibo, R.M., Erasmus Mndeme, \& Stephen E.D. Nsimba 2013. An assessment of knowledge, attitudes and practices of psychoactive substance use among secondary school students in Dodoma Municipality, Tanzania. American Journal of Research Communication. www.usajournals.com.

Rather, Y.H., Wiqar Bashir, Ajaz Ahmad Sheikh, Marya Amin \& Yasir Arafat Zahgeer. 2013. Socio-demographic and Clinical Profile of Substance Abusers Attending a Regional Drug De-addiction Centre in Chronic Conflict Area: Kashmir, India. Malays J Med Sci. 20(3): 3138. PMCID: PMC3743979.

Sharma, R.R. 2001. Knowledge of psycho active substance use; disorders among college students. Nurs J India. 92(2):29-30. PMID: 15326817

Trumbull Country. Mental Health and Recovery Board. Information on Prescription Drug Abuse.

Tsering, D., Ranabir Pal \& Aparajita Dasgupta. 2010. Substance use among adolescent high school students in India: A survey of knowledge, attitude, and opinion. J Pharm Bioallied Sci. 2(2): 137-140. doi: 10.4103/0975-7406.67005

UNAIDS 2001. Drug Use and HIV Vulnerability: Policy research and study in Asia. UNAIDS, $238 \mathrm{p}$.

Webb, E., C. H. Ashton, P. Kelly, \& F. Kamali. 1996. Alcohol and drug use in UK university students. The Lancet. 348: 922-25.

Zaman, M.S., WA Almajidi, \& Dr Hurunnaher. 2013. Knowledge on the effect of the drug abuse among the students in a selected high school in Dhaka city, Bangladesh journal of dental research and education. 3(2): 12-18. www.banglajol.info/index.php/BJDRE/article/view/ 16603. 